\title{
"The Creativity Dimension of Instructional Materials Designed by Prospective Teachers: The Comparison across Domains
}

\author{
Esen Ersoy $^{I} *$, Emine Şendurur ${ }^{2}$ and İsmail Çetin ${ }^{2}$ \\ ${ }^{1}$ Ondokuz Mayls University Education Faculty, Department of Mathematics Education, \\ Samsun/Turkey \\ ${ }^{2}$ Ondokuz Mayıs University Education Faculty, Department of Computer Education and Instructional \\ Technologies, Samsun/Turkey
}

\begin{abstract}
This study aims at revealing the creativity dimension of the materials designed and developed by the second year students studying at the department of Computer Education and Instructional Technology. A part of the participants has completed the process by designing materials in their own field, information technologies; while some of them have done so by designing materials in the field of mathematics. The data have been retrieved from an experimental study of 13 weeks. "Teaching Material Creativity Rubric" developed by the researchers, has been used as the data collection tool. The rubric has been developed in order to evaluate the creativity dimensions of products. While developing the rubric, the creative product evaluation dimensions of [14] have been a source of inspiration. The products developed by the students have been evaluated through the retrieved data, in terms of their creativity. The rubric developed includes Originality, Practicality \& Sensibility, Productivity \& Flexibility, Feasibility, Inclusiveness, and Insightfulness dimensions. In this research, the data of the aforementioned dimensions and subdimensions have been evaluated. The results present that the creativity level of the products on teaching information technologies, which have been developed by Computer Education and Instructional Technology (CEIT) students, is high. It has been argued that the creativity of domainspecifically developed materials is higher, through literature. Keywords: Material Design in Computers, Mathematics Teaching, Originality, Applicability, Creativity, Creativity and Domainswords.
\end{abstract}

\section{Introduction}

Technology supported teaching has a positive impact on students' creativity $[2,3,43]$. Enabling students to reveal their creativity through thinking in classroom settings [37] is a part of the process of education. What is important in this process is to make use of the products in the most efficient way. Positive results could be often obtained at times when students participate in the process as designers [28].

* Corresponding Author: esene@omu.edu.tr 
Although government agency, curriculum developer, teacher, pupil, and researcher have impacts on creativity [5], focusing only on the pupil's creativity might be very hard to change. In the process of education, producing as many ideas as possible and obtaining original products could bring creative products out. Thereby, creating settings, in which students can comfortably present their ideas, could contribute to increasing the number of creative products.

According to [17], for creativity in mathematical education, students' needs and learning settings should be taken into consideration. Permanent learning should be enabled through effectively using knowledge in mathematical education [10], in addition to creative products. The literature suggests that the creativity of the students, who have high performance, is also high; however, getting high grades does not always guarantee having highly creative designs [4]. Creativity is a cognitive skill owned by each and every individual. What is important is to bring that skill out. On the other hand, creativity can be improved through collaboration and technology [24]. The previously conducted studies $[3,17,20,39,42]$ suggest that creativity can be brought out throughout the process of education and training. Technology might sometimes affect the enhancement of creativity $[8,19,23,33]$, however, this effect can be either limited to such skills as writing [23] or not exist at all [31]. In order to achieve effectiveness, technology does not necessarily have to be directly used the process of design, i.e. it can have an indirect impact on the overall creativity. For example, the study of [21] has demonstrated that those who play more video games display a greater creativity.

People can mentally synthesize novel combinations of objects and their component parts, which often results in creative insights and discoveries [15,16]. Moreover, extensive brainstorming can also result in creativity [9]. In the study, the students have obtained new products by creating new combinations while developing their materials. In the settings, where synthesizing occurs, student produce creative products by combining their previous knowledge with new knowledge they acquire. Creative products are obtained through the production of original ideas. This research is of importance in terms of students' ability to produce many ideas through the materials they developed; to comfortably present their ideas; and to produce original materials, in other words, in terms of revealing the creativity of the students.

\section{Method}

The research is built upon experimental pattern. 13 week long application has been conducted with experimental group and control group students. In the experimental group, there were a mathematics expert and an IT expert; whereas in the control group, there were two IT experts. In the experimental group, materials for mathematical curriculum were developed; while in the control group, materials for IT curriculum were developed. In both groups, educational materials were designed and developed on a weekly basis. The content planned in the experimental group was prepared by the researchers respectively as following: "curriculum examination, concept map, puzzle, presentation, handbook, digital story (1 week for scenario), wiki, animation (1 week for storyboard), and worksheet".

\subsection{Study Group}

The research group consists of second year students studying at the department of Computer Education and Instructional Technology in the faculty of Education of a university located in the Black Sea region of Turkey. The study has been conducted with 76 students. In the beginning of the semester, students were randomly assigned to one of the groups, either the experimental (Math) group or control (IT) group.

\subsection{Data Collection Tools}


"Teaching Material Creativity Rubric" was developed as the data collection tool by the researchers. The rubric has been developed in order to evaluate the creativity dimensions of products. While developing the rubric, the creative product evaluation dimensions of [14] have been a source of inspiration. The rubric developed includes Originality, Practicality \& Sensibility, Productivity \& Flexibility, Feasibility, Inclusiveness, and Insightfulness subdimensions. The originality dimension has been evaluated under the categories of Wellcrafted; No copy/paste; Uncommon; No imitation/replication of something and Novel. Practicality \& Sensibility dimension is evaluated under the categories of Logical, Useful, Valuable, Understandable, Appropriate to integrate real settings, Sensitive to the needs of target learners/user friendly, Focus on solution, Implementation and Purpose. Productivity \& Flexibility dimension is examined under the categories of Time (duration of material development), Number of ideas/Idea fluency, Amount of discussion during the process, Interdisciplinary uses of material, Materials with plan-B, such as medium-free alternative uses, /producing alternative plans and Economical. Feasibility dimension is evaluated under the categories of Applicable to real content, Workability and Updatability/Sustainability. Inclusiveness dimension is examined under the categories of Elimination of bad parts of previous materials, reaching the basic standards, including the previous good features of materials, and Thoroughness. Insightfulness dimension is evaluated under Consider design principles, Consider pedagogical issues, Consider usability, Consider budget, Consider learning outcomes and Consider learners' readiness categories. In the total creativity of the rubric and the evaluations of sub-dimensions, 1:low - 5: high coding were paid regard to. The highest score to be achieved by rubric is 130 ; whereas the lowest score has been calculated as 25 . Total creativity score of the rubric and creativity scores of sub-dimensions have been calculated in the research. In this study, in order to understand the differences among creativity scores, each developed instructional material has been evaluated by researchers, and then the average has been taken as a creativity score.

So as to ensure the validity of the rubric, expert opinions have been taken. After receiving feedbacks from 6 experts in field of creativity and 4 experts in the field of mathematical education, necessary adjustments have been applied and the content validity has been ensured. In the phase of reliability, a pilot group has been chosen before the application and rubric has been applied to it. Moreover, "observer agreement" has been studied in order to ensure reliability. Computed inter-observer agreement is $71 \%$ for experiment group; and 73\% for control group, which are at the acceptable limits [34].

\subsection{Procedures}

In the beginning of the semester, students were randomly assigned to one of the groups, either the experimental group or control group. Since the students worked on projects, they were assigned to groups of 4 or 5 . During all laboratory sessions they all worked in groups. All students attended the same theoretical hours of the course, then they continued with 2 hours of practice, which required designing and developing an instructional material. In the first week, they were allowed to examine the curriculum: mathematical curriculum for the experimental group; Information Technologies curriculum for the control group. Throughout the semester, students created materials about the goals and objectives selected from the curriculum. In the following weeks, they created the materials, which can be relatively stated as: concept map, puzzle, presentation, handbook, digital story (1 week for scenario), wiki, animation (1 week for storyboard), and worksheet. They spent a week for scenario of the digital story and storyboarding of the animation. Although those were the basis of the digital story and animations, we rated them separately in terms of creativity, because their technical skills might have affected their final product. 
We uploaded weekly lab sheet on a learning management system. Students also uploaded their products or links of products to that system. There was a time restriction for all lab sessions, which took about $2 \times 45$ minutes. The products produced by the experimental group were rated by both a Math expert and an Information Technology (IT) expert. On the other hand, two IT experts evaluated the creativity of the products of the control group.

\subsection{Problem Statement}

"What is the creativity dimension of the materials developed by Computer Education and Instructional Technology (CEIT) students?"

\subsubsection{Sub-problems}

1. Is there a significant statistical difference between the total creativity scores of the materials, which were developed by Computer Education and Instructional Technology (CEIT) students for mathematical education and information technologies education?

2. Is there a significant statistical difference among sub-dimensions of the creativity of the materials developed by Computer Education and Instructional Technology (CEIT) students for mathematical education and information technologies education
a. Originality
b. Practicality \& Sensibility
c. Productivity \& Flexibility
d. Feasibility
e. Inclusiveness
f. Insightfulness?

\section{Findings Related to the First Sub Problem}

In order to determine whether there is a significant statistical difference among the total creativity scores of the materials developed for mathematical education; Two-Sample KolmogorovSmirnov $\mathrm{Z}$ test has been applied. The reason why we chose this test is due to the fact that the study has a small sampling size, i.e., and this test is more powerful in samples with less than 25 observations per group [13].The null and the alternative hypothesis are as follows:

$\mathrm{H} 0=$ There are no differences between distributions of two groups.

Ha1 $=$ There are significant differences between distribution of two groups.

$\mathrm{Ha} 2=$ The cumulative distribution function (cdf) of the distribution of group 1 (IT material development) is larger than the cdf of the distribution of group 2 (math material development), in terms of creativity scores.

The results of the test indicate that there is a single maximum difference between two distributions, which are IT instructional material development group and math instructional material development group. In other words, two-sample Kolmogorov-Smirnov $\mathrm{Z}$ test followed the two groups' distributions for creativity (Dcreativity $=1.00, \mathrm{~N}=8$ for each group, and $\mathrm{p}<.05$ ). Considering critical value for equal size at .05 alpha level, we can confirm that the absolute value (D $=1.00)$ of the test statistic exceeds the critical two-tailed value (Dcritical $=.63$ ), which means rejecting the equality of distributions. Moreover, the computed absolute value $(\mathrm{D}=1.00)$ is greater than the one-tailed critical value (Dcritical $=.50$ ), which means cumulative distribution function (cdf) of IT group distribution is larger than cdf of math group distribution, in terms of total creativity scores. The output of the test is summarized in Table 1. 
Table 1.Two-sample kolmogorov-smirnov $\mathrm{Z}$ test for total creativity scores

\begin{tabular}{|c|c|c|}
\hline & & Creativity \\
\hline Most & Absolute & 1.00 \\
Extreme & Positive & 1.00 \\
Differences & Negative & .000 \\
\hline & & \\
Kolmogorov- & & 2.00 \\
Smirnov Z & & .001 \\
Asymp. Sig. & & \\
(2-tailed) & & \\
\hline
\end{tabular}

\subsection{Findings Related to the Second Sub Problem}

The findings belonging to the second sub-problem are stated below according to the subdimensions of the materials developed. For each sub-dimension of creativity, the following hypothesis are tested with Two-Sample Kolmogorov-Smirnov Z test.

$\mathrm{H} 0=$ There is no differences between distribution of two groups.

$\mathrm{Ha} 1=$ There are significant differences between distribution of two groups.

$\mathrm{Ha} 2=$ The cdf of the distribution of group 1 is larger than the cdf of the distribution of group 2 in terms of originality, practicality-sensibility, productivity-flexibility, feasibility, inclusiveness, and insightfulness.

a. In order to determine whether there is a significant statistical difference among the originality scores of the materials developed for mathematical education; Two-Sample Kolmogorov-Smirnov $\mathrm{Z}$ test has been applied. The test shows that the maximum absolute difference in originality distribution of two groups is significant (Doriginality $=.75$, Dcritical $=.63, \mathrm{~N}=8$ for each group, and $\mathrm{p}<.05)$. Since the computed absolute value is greater than the one-tailed critical value (Doriginality $=.75$, Dcritical $=.50, \mathrm{~N}=8$ for each group, and $\mathrm{p}<.05$ ), it can be concluded that the cdf of IT group distribution is larger than cdf of math group distribution in terms of total originality scores. The output of the test is summarized in Table 2.

Table 2. Two-sample kolmogorov-smirnov $\mathrm{Z}$ test for originality scores

\begin{tabular}{|l|l|l|}
\hline \multicolumn{2}{|c|}{} & Creativity \\
\hline \multirow{3}{*}{ Most Extreme Differences } & Absolute & .750 \\
\cline { 2 - 3 } & Positive & .750 \\
\cline { 2 - 3 } & Negative & .000 \\
\hline Kolmogorov-Smirnov Z & 1.50 \\
\hline Asymp. Sig. (2-tailed) & .022 \\
\hline
\end{tabular}

b. In order to determine whether there is a significant statistical difference among the practicality and sensibility scores of the materials developed for mathematical education; Two-Sample Kolmogorov-Smirnov Z test has been applied. The test shows that the maximum absolute difference in practicality and sensibility distribution of two groups is significant (DPrac\&Sens $=.88$, Dcritical $=.63, \mathrm{~N}=$ 8 for each group, and $\mathrm{p}<.05)$. Since the computed absolute value is greater than the one-tailed critical value (DPrac\&Sens $=.88$, Dcritical $=.50, \mathrm{~N}=8$ for each group, and $\mathrm{p}<.05$ ), it can be concluded that the cdf of IT group distribution is larger than cdf of math group distribution in terms of total practicality and sensibility scores. The output of the test is summarized in Table 3. 
Table 3. Two-sample kolmogorov-smirnov z test for practicality \& sensibility scores

\begin{tabular}{|l|l|l|}
\hline \multicolumn{2}{|c|}{} & Creativity \\
\hline Most Extreme Differences & Absolute & .875 \\
\cline { 2 - 3 } & Positive & .875 \\
\cline { 2 - 3 } & Negative & .000 \\
\hline Kolmogorov-Smirnov Z & 1.75 \\
\hline Asymp. Sig. (2-tailed) & .004 \\
\hline
\end{tabular}

c. In order to determine whether there is a significant statistical difference among the productivity and flexibility scores of the materials developed for mathematical education; Two-Sample Kolmogorov-Smirnov Z test has been applied. The test shows that the maximum absolute difference in productivity and flexibility distribution of two groups is significant (DProd\&Flex $=.88$, Dcritical $=.63, \mathrm{~N}=8$ for each group, and $\mathrm{p}<.05)$. Since the computed absolute value is greater than the one-tailed critical value (DProd\&Flex $=.88$, Dcritical $=.50, \mathrm{~N}=$ 8 for each group, and $\mathrm{p}<.05)$, it can be concluded that the cdf of IT group distribution is larger than cdf of math group distribution in terms of total productivity and flexibility scores. The output of the test is summarized in Table 4.

Table 4. Two-sample kolmogorov-smirnov z test for productivity \& flexibility scores

\begin{tabular}{|l|l|l|}
\hline \multicolumn{2}{|c|}{} & Creativity \\
\hline Most Extreme Differences & Absolute & .875 \\
\cline { 2 - 3 } & Positive & .875 \\
\cline { 2 - 3 } & Negative & .000 \\
\hline Kolmogorov-Smirnov Z & 1.75 \\
\hline Asymp. Sig. (2-tailed) & .004 \\
\hline
\end{tabular}

d. In order to determine whether there is a significant statistical difference among the feasibility mscores of the materials developed for mathematical education; Two-Sample Kolmogorov-Smirnov $\mathrm{Z}$ test has been applied. The test shows that the maximum absolute difference in feasibility distribution of two groups is significant (DFeasibility $=.88$, Dcritical $=.63, \mathrm{~N}=8$ for each group, and $\mathrm{p}<.05)$. Since the computed absolute value is greater than the one-tailed critical value (DFeasibility $=.88$, Dcritical $=.50, \mathrm{~N}=8$ for each group, and $\mathrm{p}<.05$ ), it can be concluded that the cdf of IT group distribution is larger than cdf of math group distribution in terms of total feasibility scores. The output of the test is summarized in Table 5.

Table 5. Two-sample kolmogorov-smirnov $\mathrm{z}$ test for feasibility scores

\begin{tabular}{|l|l|l|}
\hline \multicolumn{2}{|c|}{} & Creativity \\
\hline \multirow{2}{*}{ Most Extreme Differences } & Absolute & .875 \\
\cline { 2 - 3 } & Positive & .875 \\
\cline { 2 - 3 } & Negative & .000 \\
\hline Kolmogorov-Smirnov Z & 1.75 \\
\hline Asymp. Sig. (2-tailed) & .004 \\
\hline
\end{tabular}

e. In order to determine whether there is a significant statistical difference among the inclusiveness scores of the materials developed for mathematical education; Two-Sample Kolmogorov-Smirnov Z test has been applied. The test shows that 
the maximum absolute difference in inclusiveness distribution of two groups is significant (Dinclusiveness $=.88$, Dcritical $=.63, \mathrm{~N}=8$ for each group, and $\mathrm{p}<$ $.05)$. Since the computed absolute value is greater than the one-tailed critical value (Dinclusiveness $=.88$, Dcritical $=.50, \mathrm{~N}=8$ for each group, and $\mathrm{p}<.05$ ), it can be concluded that the cdf of IT group distribution is larger than cdf of math group distribution in terms of total inclusiveness scores. The output of the test is summarized in Table 6.

Table 6. Two-sample kolmogorov-smirnov z test for inclusiveness scores

\begin{tabular}{|l|l|l|}
\hline \multicolumn{2}{|c|}{} & Creativity \\
\hline \multirow{2}{*}{ Most Extreme Differences } & Absolute & .875 \\
\cline { 2 - 3 } & Positive & .875 \\
\cline { 2 - 3 } & Negative & .000 \\
\hline Kolmogorov-Smirnov Z & 1.75 \\
\hline Asymp. Sig. (2-tailed) & .004 \\
\hline
\end{tabular}

f. In order to determine whether there is a significant statistical difference among the insightfulness scores of the materials developed for mathematical education; Two-Sample Kolmogorov-Smirnov Z test has been applied. The test shows that the maximum absolute difference in insightfulness distribution of two groups is significant $\left(\mathrm{D}_{\text {insightfulness }}=1.00, \mathrm{D}_{\text {critical }}=.63, \mathrm{~N}=8\right.$ for each group, and $\left.\mathrm{p}<.05\right)$. Since the computed absolute value is greater than the one-tailed critical value $\left(D_{\text {insightfulness }}=1.00, D_{\text {critical }}=.50, \mathrm{~N}=8\right.$ for each group, and $\left.\mathrm{p}<.05\right)$, it can be concluded that the cdf of IT group distribution is larger than cdf of math group distribution in terms of total insightfulness scores. The output of the test is summarized in Table 7.

Table 7. Two-sample kolmogorov-smirnov z test for insightfulness scores

\begin{tabular}{|l|l|l|}
\hline \multicolumn{2}{|c|}{} & Creativity \\
\hline \multirow{2}{*}{ Most Extreme Differences } & Absolute & 1.00 \\
\cline { 2 - 3 } & Positive & 1.00 \\
\cline { 2 - 3 } & Negative & .000 \\
\hline Kolmogorov-Smirnov Z & 2.00 \\
\hline \multicolumn{2}{|l}{ Asymp. Sig. (2-tailed) } & .001 \\
\hline
\end{tabular}

\section{Discussion and Conclusion}

Technology is, in essence, a manifestation of human creativity. Thus, an important way, in which students can come to understand it, would be by engaging in acts of technological creation. Technology as a context for creativity is an important area of research [26]. Although there are many ways to evaluate creativity, in this study we followed the dimensions offered by [14]. The reason why we used those criteria is because of its focus on evaluation of product development process. Basically, there are six dimensions including originality, practicality and sensibility, productivity and flexibility, feasibility, inclusiveness, and insightfulness.

In this study, it has been aimed to reveal prospective IT teachers' creativity in their domain-specific and domain-general material designs. So as to reveal creativity, it is a necessity to determine individual and social skills; to allow for self-induced ideas; to classify similarities and differences in a versatile manner; and to allow for flexible thinking (Meissner, 2006). The results suggest that the creativity scores of the products developed by CEIT students for IT education are higher than those of the products developed for mathematical education. This might be due to the fact that CEIT students have a better command of information technologies. Even though, there are studies in the literature 
claiming that creativity is not domain-specific [30], there also exist studies, which propose that interdisciplinary approaches along with deep field knowledge contribute to creativity [32]. In this study, the fact that CEIT students have developed more creative materials in their own field might be because they do not find themselves adequate in the field of mathematics. It is possible to say that the aforementioned finding is contrary to those of [30] and partially supports the point of view of [32].

Originality dimension refers to uncommon products that are somehow surprising, wellcrafted, novel or at least innovative. An original instructional material should not be the replication or imitation of some other material; therefore copying and pasting any content are not welcome, neither. The results of the study demonstrate that the products developed by CEIT students for IT education are original, in other words; well-designed, innovative, and creative. Although, the creativity can be enhanced through the use of computer-aided instruction in the field of mathematics [2], the involvement of computers in the design and development process does not seem to contribute to the creativity of mathematical materials. This may be result from the fact that CEIT students have examined or used many educational materials about their own field. In today's world, on-hand materials about coding, graphic design, animation etc. can be easily accessed through platforms such as YouTube and Facebook by students, who wish to develop themselves in those fields. On the other hand, the number of digital materials about mathematics at higher education level are less than that of the IT materials. For that reason, the students might have tended to develop materials different from those they had seen before, while developing cliché materials for mathematics since they were unable to make comparisons.

Practicality and sensibility dimension refers to useful or valuable products based upon a logical or understandable background. Such a product is assumed to have high quality. Offered solutions of the product should be sensitive to the needs of target learners and appropriate to integrate real settings. The results indicate that the products developed by CEIT students about IT education is more applicable and understandable when compared to the other group. This might be due to the fact that the students have a command of their own field. For example, since mathematics is a more abstract field, CEIT students' interdisciplinary approach to the subject and materialization and ability to reflect it on the material could prevent the emergence of practical and sensible products.

Productivity and flexibility dimension emphasizes on idea fluency as well as the amount of discussion. In addition to the time spent for material development, interdisciplinary uses of developed material and alternative plans are also important in this dimension. The results of the study suggest that the products developed by CEIT students about IT education is more productive when compared to those of the other group. According to the previous studies [22,29]; it is asserted that the productivity and flexibility dimensions of the materials developed will come to the light within a certain period of time. In the study conducted, a 13-week application has been used. Throughout this process, the students have worked in groups. Their idea fluency, discussion amounts, and the time they spared for preparing materials have changed in time. The difference between two groups might be due to the fact that they had to spend extra time in order to comprehend the conceptions about mathematics and to reflect them in the best possible way.

Feasibility dimension focuses on how applicable the product to real content. It is also important to create a product that is workable and sustainable. Especially in the field of information technology, developed instructional materials should be easily kept up-to-date. The results indicate that the products developed by CEIT students about IT education is more applicable when compared to the other group. The previous studies [1] support the research results of [40]. 
Inclusiveness dimension refers to thoroughness of the product. It should at least reach the basic standards of the previously available materials by eliminating the bad features. Thereby, it has been observed that the integration dimension of the products developed by CEIT students about IT education are more comprehensive. This, again, might result from the fact that IT materials are more easily and comfortably accessed by the students.

Insightfulness dimension refers to consideration of certain issues related to instructional material development. In our study, these consist of design principles, pedagogical issues, usability, budget, learning outcomes, and learners' readiness level. The results indicate that in the process of developing educational materials, the products developed by CEIT students about IT education are more understandable. Some of the previous studies [27] support this research.

The experimental researches conducted in the field of technological education $[7,8,11,19,25,35,38]$; have also demonstrated the significance of the creativity dimension. Since evaluating the creativity of students at an informational dimension can only be done through the planned course contents [11]; the educational process should be designed by the experts in the field. In this study, the lesson plans prepared for IT education are also created in order to determine creativity. The plans prepared contain curriculum examination, concept map, puzzle, presentation, handbook, digital story (1 week for scenario), wiki, animation (1 week for storyboard), and worksheet. The application have been relatively applied to both groups. According to the retrieved results, the creativity, originality, practicality \& sensibility, productivity \& flexibility, feasibility, inclusiveness, and insightfulness dimensions of the products prepared for IT education are better than those of the other products. Although both groups were provided with equal laboratory opportunities, their creativity scores displayed differences since the fields, in which they developed materials, were also different. The students did not often spend extra time for understanding/discovering the conceptions or terms while developing materials in their own field. However, they spent extra effort for understanding the conceptions or terms and presenting them in the right manner, before stepping up to the phase of developing materials in a field, which is different from their own field and can be considered to be quite an abstract field. This might have made them feel limited or inadequate at times. The significant points that can be recommended based on the results of this study are as follows:

*the prospective teachers should be provided with adequate support in their fields throughout the process of designing and developing materials in interdisciplinary studies,

*having proper technical skills does not always guarantee for students to develop creative materials,

* for the materials to be developed in interdisciplinary studies, good examples of the field should be brought together and presented,

*important points regarding the subject should be elaborated before developing materials for abstract subjects,

The scope of the study has been determined as CEIT students; and one of the groups has been expected to develop materials in a field different from their own field. Different departments and fields could be included in the study in order to make it more comprehensive and to evaluate the results in other fields. One of the restrictions of the study has been the fact that the students have conducted a group work. More detailed observations could be conducted through creating smaller groups. Besides that, the technical skills of the students and their reflections on creativity could also be examined. 
The creativity dimensions of the products developed in creative learning settings are often high $[6,18,12,36,41]$. These results display parallelism with the research. As [17] discusses student needs and setting are required for creativity. In the research, a learning setting and plan, which meet the needs of the students for learning, have been prepared. The lesson plans, which reveal the creativity of students, have been applied to the students for 13 weeks. It is possible to say that the study has yielded positive results in terms revealing the creativity of the students and the effectiveness of the education.

\section{References}

1. Alpert, D., Bitzer, D.L. Advances in Computer-based Education. American Association for the Advancement of Science. 167, 1582-1590. (1970).

2. Aqda, M.F., Hamidi, F., Rahimi, M. The comparative effect of computer-aided instruction and traditional teaching on student's creativity in math classes. Procedia Computer Science, 3, 266270. (2011).

3. Aslan, A.E., Puccio, G.J. Developing and Testing a Turkish Version of Torrance's Test of Creative Thinking: A Study of Adults. USA: Journal of Creative Behavior. 40 (3), 163-178. (2006).

4. Atkinson, S. Does the need for high levels of performance curtail the development of creativity in design and technology project work? International Journal of Design and Education. 10, 255281 (2000).

5. Barlex, D. Creativity in school design and technology in England: a discussion of influences. International Journal of Technology Design Education, 17, 149-162 (2007).

6. Besemer, Susan P., Donald J. Treffinger. Analysis of Creative Products: Review and Synthesis The Journal of Creative Behavior 15 (3), 158-178 (1981),

7. Besemer, S.P., O'Quin, K. The development, reliability and validity of the revised creative product semantic scale. Creativity Research Journal, 2, 268-279 (1989).

8. Betz, J.A. Computer games: Increase learning in an interactive multidisciplinary environment. Journal of Technology Systems, 24 (2), 195-205 (1996).

9. Bryant, C. A 21st-century art room: the remix of creativity and technology. Art Education, 63 (2), 43-48 (2010).

10. English, L.D., Halford, G.S. Mathematics Education Models and Processes, Models and processes. Mahwah, NJ : Lawrence Erlbaum, (1995).

11. Eyadat, W.M., Eyadat, Y.A. Instructional technology and creativity among university students: the missing link. World Journal on Educational Technology, 2 (2), 87-99 (2010)

12. Feldhusen, John F., Pamela R. Clinkenbeard. Creativity instructional materials: A review of research. The Journal of Creative Behavior 20 (3) 153-182, (1986).

13. Field, A. Discovering Statistics: Using SPSS (2nd Ed.). London: Sage (2005).

14. Finke, R.A., Ward, T.B., Smith, S.M. Creative Cognition: Theory, Research, and Applications, Cambridge, MA: MIT Press, (1996).

15. Finke, R.A. Imagery, Creativity and Emergent Structure. Consciousness and Congnition 5, 381393. Article No. 0024. (1996).

16. Finke, R.A., Slayton, K. Explorations of creative visual synthesis in mental imagery. Memory \& Cognition, 16 (3), 252-257, (1988).

17. Higginston, W. Creativity in Mathematics Education: The Role of the Teacher. $9^{\text {th }}$ International Congress on Mathematical Education, Tokyo, (2000).

18. Hill, A. Community-based Projects in Technology Education: An Approach for Relevant Learning. Paper presented at the International Workshop Seminar for Scholars in Technology Education, Washington, DC, (1998).

19. Howe, R. (1992). Uncovering the creative dimensions of computer-graphic design products. Creativity Research Journal, 5 (3), 233-243.

20. Isaksen, S.G., Puccio, G.J. Adaption-Innovation And The Torrance Tests of Creative Thinking: The Level-Style Issue Revisited. Psychological Reports 63, 659-670 (1988). 
21. Jackson, L.A., Witt, E.A., Games, A.I., Fitzgerald, H.E., Van Eye, A., Zhao, Y. Information technology use and creativity: findings from the children and technology Project. Computers in Human Behavior, 28(2), 370-376, (2012).

22. Jang, S. Exploration of secondary students' creativity by integrating web-based technology into an innovative science curriculum. Computers \& Education. 52, 247-255. (2008).

23. Joram, E., Woodruff, E., Bryson, M., Lindsay, P. The effects of revising with a Word processor on writing composition. Research in the Teaching of English, 26(2), 167-192 (1992).

24. Karakaya, A.F., Demirkan, H. Collaborative digital environments to enhance the creativity of designers. Computers in Human Behavior, 42, 176-186 (2015).

25. Lewis, T. Creativity: A Framework for the Design/problem Solving Discourse in Technology Education. Journal of Technology Education, 17(1), 35-52 (2006).

26. Lewis, T. Research in technology education: Some areas of need. Journal of Technology Education, 10 (2), 41-56, (1999).

27. Lewis, T., Petrina, S., Hill, A.M. Problem Posing-Adding a Creative Increment to Technological Problem Solving. Journal of Industrial Teacher Education. 36 (1) (1998).

28. Liu, M., Hsiao, Y.P. Middle School Students as Multimedia Designers: A Project-Based Learning Approach. Journal of Interactive Learning Research, 13(4), 311-337 (2002).

29. Lubart, T.I., Sternberg, R.J. An investment approach to creativity: theory and data. In S. M. Smith, T. B. Ward and R. A. Finke (Eds). The creative cognition approach (pp. 271-302). San Diego: Academic Press (1995).

30. Lucas, B. Creative teaching, teaching creativity and creative learning. In A. Craft, B. Jeffrey, M. Liebling (Eds.) Creativity in Education. London: Continuum. (2001).

31. Michael, K.Y. The Effect of a Computer Simulation Activity versus a Hands-on Activity on Product Creativity in Technology Education. Journal of Technology Education. 13 (1), 31-43. (2001).

32. Mishra, P., Henriksen, D., The Deep-Play Research Group Rethinking technology and creativity in the $21^{\text {st }}$ century: on being in-disciplined. TechTrends, 56(6), 18-21. (2012).

33. Neo, M., Neo, T.-K. Exploring students' creativity and design skills through multimedia project: a constructivist approach in a Malaysian classroom. Design and Technology: An International Journal, 18(3), 48-59. (2013).

34. Neuendorf, K. A. The content analysis guidebook. Thousand Oaks, California: Sage Publications. (2002). - See more at: http://digital-activism.org/2013/05/picking-the-bestintercoder-reliability-statistic-for-your-digital-activism-content-analysis/\#sthash.9Hb1j1RG.dpuf

35. Ottenbreit-Leftwich, A.T., Glazewski, K.D., Newby, T. J., Ertmer, P.A. Teacher value beliefs associated with using technology: Addressing Professional and student needs. Computers \& Education 55, 1321-1335, (2010).

36. Parnes, S.J. The Creative Studies Project. In Isaksen, S.G. (Ed.), Frontiers of Creativity Research: Beyond the basic (Pp. 156-188). Buffalo, NY: Bearly Limited. (1987).

37. Quitadamo, I.J. Critical Thinking in Higher Education: The Influence of Teaching Styles and Peer Collaboration on Science and Math Learning. Washington State University. (2002).

38. Shuell, T. J., Farber, S. L. Students' perceptions of technology use in college courses. Journal of Educational Computing Research, 24, 21-30. (2001).

39. Sosik, J.J., Kahai, S.S., Avolio, B.J. Transformational Leadership and Dimension of Creativity: Motivating Idea Generation in Computer-Mediated Groups. Creativity Research Journal. 11(2), 111-121, (1998).

40. Sun, p., Tsai, R.J., Finger, G., Chen, Y., Yeh, D. What drives o successful e-Learning? An empirical investigation of the critical factors influencing learner satisfaction. Computers \& Education. 50( 4). 1183-1202, (2008).

41. Şendurur, E., Ersoy, E., Çetin, İ. The design and development of creative instructional materials: the role of domain familiarity for creative solutions. Int $\mathrm{J}$ Technol Des Educ. DOI 10.1007/s10798-016-9391-y (2016).

42. Törnkvist, S. Creativity: Can It Be Taught? The Case of Engineering Education. European Journal of Engineering Education. 23(1), 5-12, (1998). 